Corrigendum

\title{
Corrigendum to "Two-Year Outcome of Aflibercept in Patients with Pigment Epithelial Detachment due to Neovascular Age-Related Macular Degeneration (nAMD) Refractory to Ranibizumab"
}

\author{
Thi Ha Chau Tran $\mathbb{D D}^{1}{ }^{1}$ Stéphane Dumas, ${ }^{2}$ and Florence Coscas ${ }^{3}$ \\ ${ }^{1}$ Ophthalmology Department, Lille Catholic Hospitals, Lille Catholic University, Lille, France \\ ${ }^{2}$ Clinique de la Louvière, Lille, France \\ ${ }^{3}$ Centre Ophtalmologique de l'Odéon, Université Paris-Est Créteil (UPEC), Paris, France \\ Correspondence should be addressed to Thi Ha Chau Tran; tran.hachau@ghicl.net \\ Received 24 April 2018; Accepted 27 May 2018; Published 8 July 2018 \\ Copyright (c) 2018 Thi Ha Chau Tran et al. This is an open access article distributed under the Creative Commons Attribution \\ License, which permits unrestricted use, distribution, and reproduction in any medium, provided the original work is \\ properly cited.
}

In the article titled "Two-Year Outcome of Aflibercept in Patients with Pigment Epithelial Detachment due to Neovascular Age-Related Macular Degeneration (nAMD) Refractory to Ranibizumab" [1], there were errors, which should be corrected as follows:

(i) In Abstract, the term "(DEP)" should be "(PED)."

(ii) In Results, "Change of CRT did not reach the significant difference at any time point of the study
(M6: $312 \pm 91 \mu \mathrm{m}, \mathrm{NS} ; \mathrm{M} 12: 312 \pm 84 \mu \mathrm{m}, \mathrm{NS} ; \mathrm{M} 24$ : $312 \pm 12.3, \mathrm{NS}$ )" should be corrected to "Change of CRT did not reach the significant difference at any time point of the study (M6: $312 \pm 14 \mu \mathrm{m}, \mathrm{NS} ; \mathrm{M} 12$ : $313 \pm 13.9 \mu \mathrm{m}, \mathrm{NS} ; \mathrm{M} 24: 305 \pm 76$, NS)."

(iii) In Table 2, there were errors in the values in the third, fourth, and sixth columns. The corrected table and its description are shown below.

TABLE 2: Comparison of functional and morphologic changes from time of switch to 24 months.

\begin{tabular}{|c|c|c|c|c|c|c|c|c|c|}
\hline Central macular thickness $(\mu \mathrm{m})$ & $\begin{array}{c}\text { Baseline } \\
N=44\end{array}$ & $\begin{array}{c}\text { Month } 3 \\
N=44\end{array}$ & $P$ & $\begin{array}{c}\text { Month } 6 \\
N=44\end{array}$ & $P$ & $\begin{array}{c}\text { Month } 12 \\
N=44\end{array}$ & $P$ & $\begin{array}{c}\text { Month } 24 \\
N=38\end{array}$ & $P$ \\
\hline ETDRS & $64.4 \pm 13.1$ & $67.6 \pm 12.3$ & 0.002 & $67.3 \pm 11$ & 0.005 & $64.8 \pm 13$ & 0.6 & $61.4 \pm 13.8$ & 0.2 \\
\hline Central macular thickness $(\mu \mathrm{m})$ & $313 \pm 13$ & $301 \pm 77$ & 0.2 & $312 \pm 14.2$ & 0.9 & $313 \pm 13.9$ & 0.9 & $305 \pm 76$ & 0.6 \\
\hline Macular volume $\left(\mathrm{mm}^{3}\right)$ & $7.70 \pm 2.2$ & $7.75 \pm 0.16$ & 0.8 & $7.8 \pm 0.16$ & 0.6 & $7.85 \pm 0.16$ & 0.4 & $7.8 \pm 0.65$ & 0.3 \\
\hline PED height $(\mu \mathrm{m})$ & $224.7 \pm 18.5$ & $198.5 \pm 19.5$ & 0.025 & $190 \pm 17.3$ & 0.05 & $224 \pm 21$ & 0.27 & $200 \pm 19$ & 0.14 \\
\hline Subfoveal choroidal thickness $(\mu \mathrm{m})$ & $179 \pm 68$ & & & & & $158 \pm 67$ & 0.2 & $174 \pm 56$ & 0.5 \\
\hline
\end{tabular}

Data are mean \pm SD unless indicated otherwise. $P$ : continuous variables compared by independent samples $t$-test from baseline; ETDRS: Early Treatment Diabetic Retinopathy Score; PED: pigment epithelial detachment. 


\section{References}

[1] T. H. C. Tran, S. Dumas, and F. Coscas, "Two-year outcome of aflibercept in patients with pigment epithelial detachment due to neovascular age-related macular degeneration (nAMD) refractory to ranibizumab," Journal of Ophthalmology, vol. 2017, Article ID 8984313, 8 pages, 2017. 


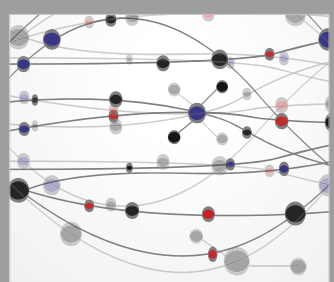

The Scientific World Journal
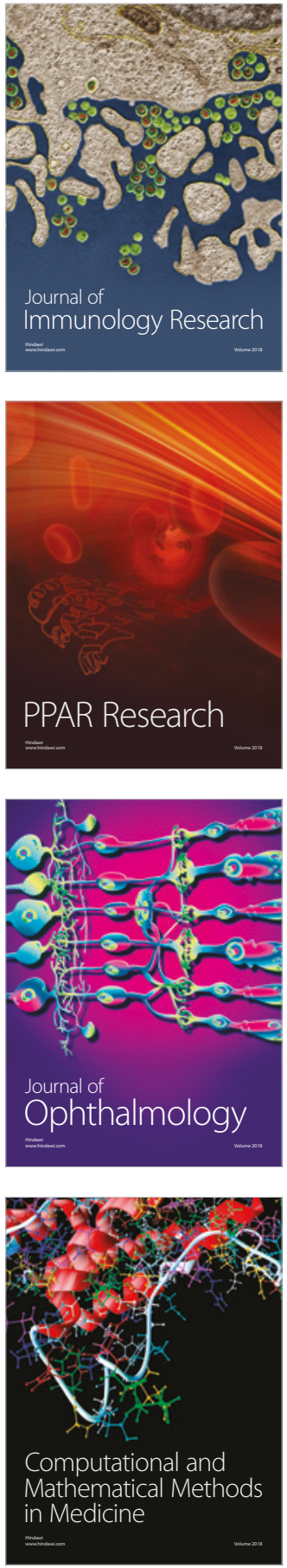

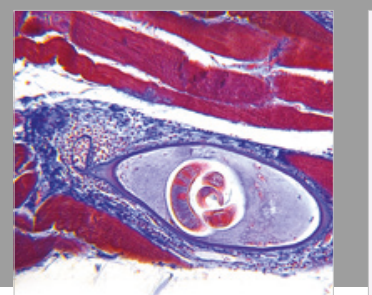

Gastroenterology Research and Practice

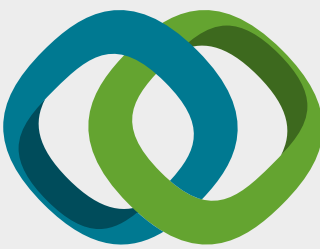

\section{Hindawi}

Submit your manuscripts at

www.hindawi.com
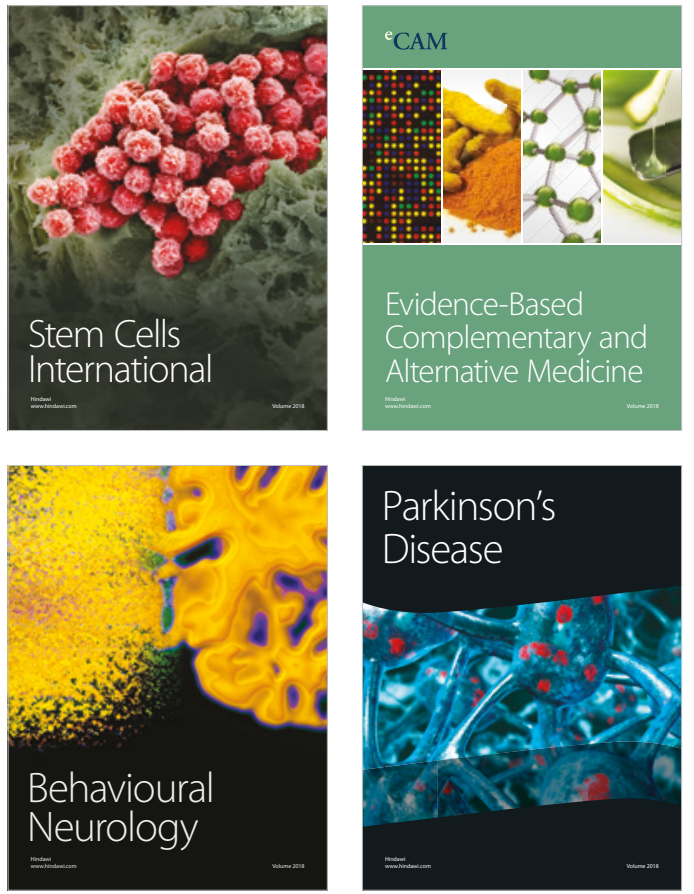

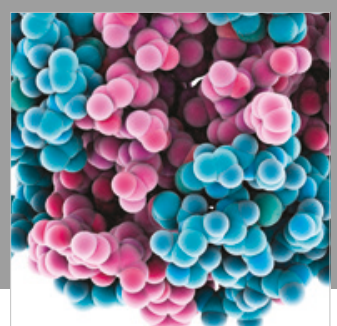

ournal of

Diabetes Research

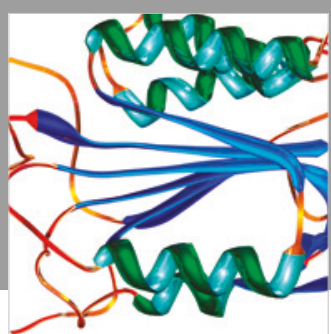

Disease Markers
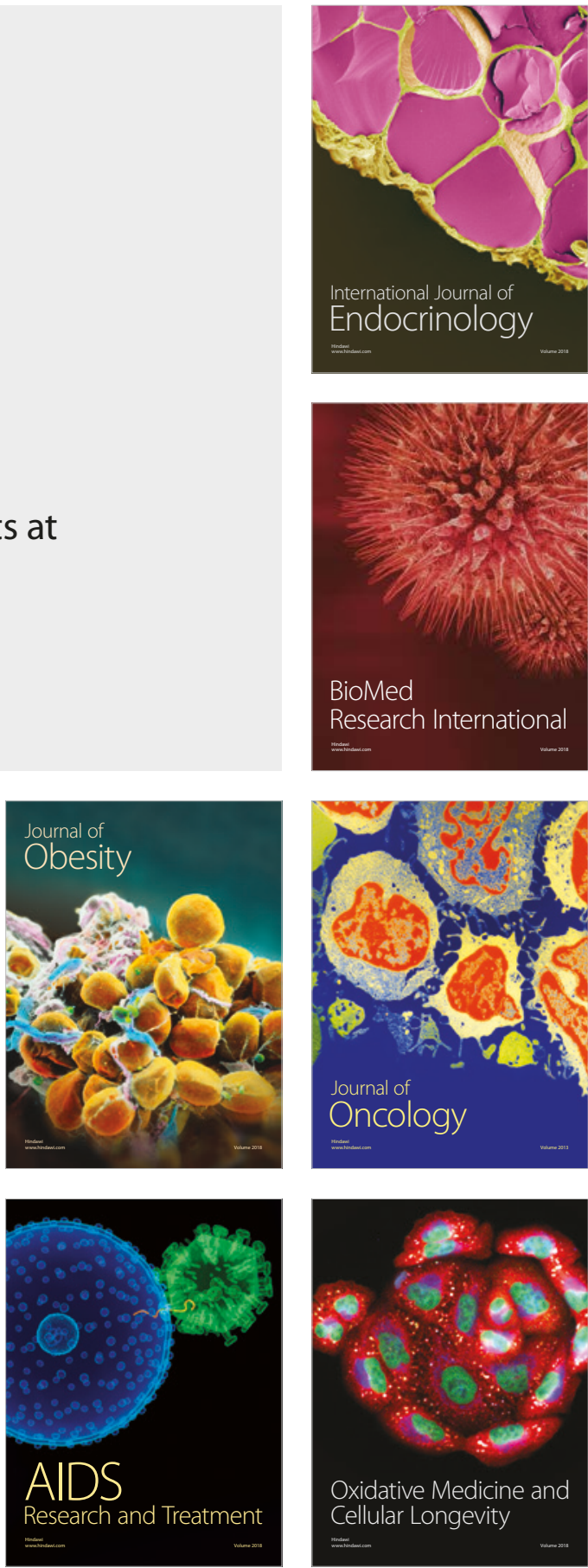